\title{
National Human Genome Research Institute
}

National Cancer Institute

\section{Source}

National Cancer Institute. National Human Genome Research Institute. NCI Thesaurus. Code C82617.

An institute within the National Institutes of Health $(\mathrm{NIH})$ that led NIH's contribution to the International Human Genome Project. Since the completion of this project its mission has expanded to encompass a broad range of studies aimed at understanding the structure and function of the human genome and its role in health and disease. To that end it supports the development of resources and technology that will accelerate genome research and its application to human health. A critical part of its mission continues to be the study of the ethical, legal and social implications (ELSI) of genome research. 